\title{
Intra Capsular but Extra Synovial Foreign Body in the Knee Joint
}

\author{
Gunasekaran Kumar* \\ Consultant Orthopaedic Surgeon, Royal Liverpool University Hospital, United Kingdom
}

*Corresponding author: Gunasekaran Kumar, MS Orth, FRCSGlasg (Tr\&Orth), Consultant Orthopaedic Surgeon, Royal Liverpool University Hospital, Prescot Street, Liverpool L7 8XP, United Kingdom, Tel: 0044-7531004099, E-mail: gunasekarankumar@hotmail.com

\begin{abstract}
Intra-articular foreign bodies especially in the knee joint are well reported. Knee joint is commonly involved due to the large joint area and also due to it being a superficial joint. Foreign bodies enter the joint either by direct inoculation or migration from nearby tissues. Potential complications of Intra-articular foreign bodies include infection, damage to articular surface and locking of joint. This is a report on a penetrating injury to the knee resulting in an intra capsular but extra synovial foreign body. A 10 -year-old boy fell on to railing and sustained injury to the right knee. The railing broke and part of it was protruding out of the knee. Radiographs showed that the piece of railing had lodged into the lateral compartment of the knee. At surgery the part of railing was found to between the capsule and synovium of the knee joint. This was successfully removed. Synovial lining was found to be intact with intraoperative saline test of the joint that showed no leakage of fluid in to the wound. Capsule was closed and rest of the left open. Patient underwent a further debridement and delayed closure at 48 hours. Patient made an uneventful recovery. This report is presented to show that all Intra-articular foreign bodies are not intrasynovial.
\end{abstract}

\section{Keywords}

Foreign body, Joint, Knee, Open wound, Penetrating wound, Extra synovial

\section{Introduction}

Limb injuries from penetrating foreign bodies are common. Intra-articular foreign bodies often enter the joint due to trauma, either as a direct injury or by migration from either nearby soft tissues [1]. Intra-articular foreign bodies are a variety ranging from plastic bottle cap [2], varying types of projectiles [3-5], broken instruments [6], broken implants [7], broken guide wire [8], glass piece $[9,10]$, lead pencil [11], gear shift [12] broken needle [13], thorn [14-16] and mercury [17]. These can be either present acutely or after some time has passed [18].

Intra-articular foreign bodies require removal to reduce risk of infection and avoid secondary damage to articular cartilage. Occasionally, smaller foreign bodies could become loose bodies causing mechanical symptoms.

\section{Case Report}

A 10-year-old boy while playing on a wall fell on the railing and sustained an injury to his right knee. He presented to casualty with a piece of metal protruding out of his flexed right knee. Primary and secondary survey did not reveal any other injuries. On examining the right knee there was a transverse laceration of about $4 \mathrm{~cm}$ at the level of lateral joint line with a rusted metal rod protruding out of the laceration (Figure $1 \mathrm{a}$ and Figure 1b). The knee was flexed at about $140^{\circ}$ and no movement could be achieved due to pain. There was no distal neurovascular deficit. Rest of the right lower limb was normal. Radiographs showed a bent metal rod that appeared to be in the lateral compartment of the right knee (Figure 2). Patient underwent exploration of the wound and removal of the foreign body under general anaesthesia within 4 hours of the incident. Per-operative findings were show a dirty wound which was extended longitudinally, and the metal rod followed deep into the wound and removed. The metal rod had gone through the potential space between capsule and synovial lining of the knee joint. Exploration of this space did not show any breach of synovium (Figure 3). Thirty $\mathrm{mL}$ of Normal saline was infiltrated into the right knee from

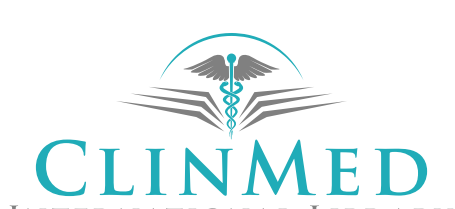

INTERNATIONAL LIBRARY
Citation: Kumar G (2018) Intra Capsular but Extra Synovial Foreign Body in the Knee Joint. Trauma Cases Rev 4:062. doi.org/10.23937/2469-5777/1510062

Accepted: July 09, 2018: Published: July 11, 2018

Copyright: (C) 2018 Kumar G. This is an open-access article distributed under the terms of the Creative Commons Attribution License, which permits unrestricted use, distribution, and reproduction in any medium, provided the original author and source are credited. 

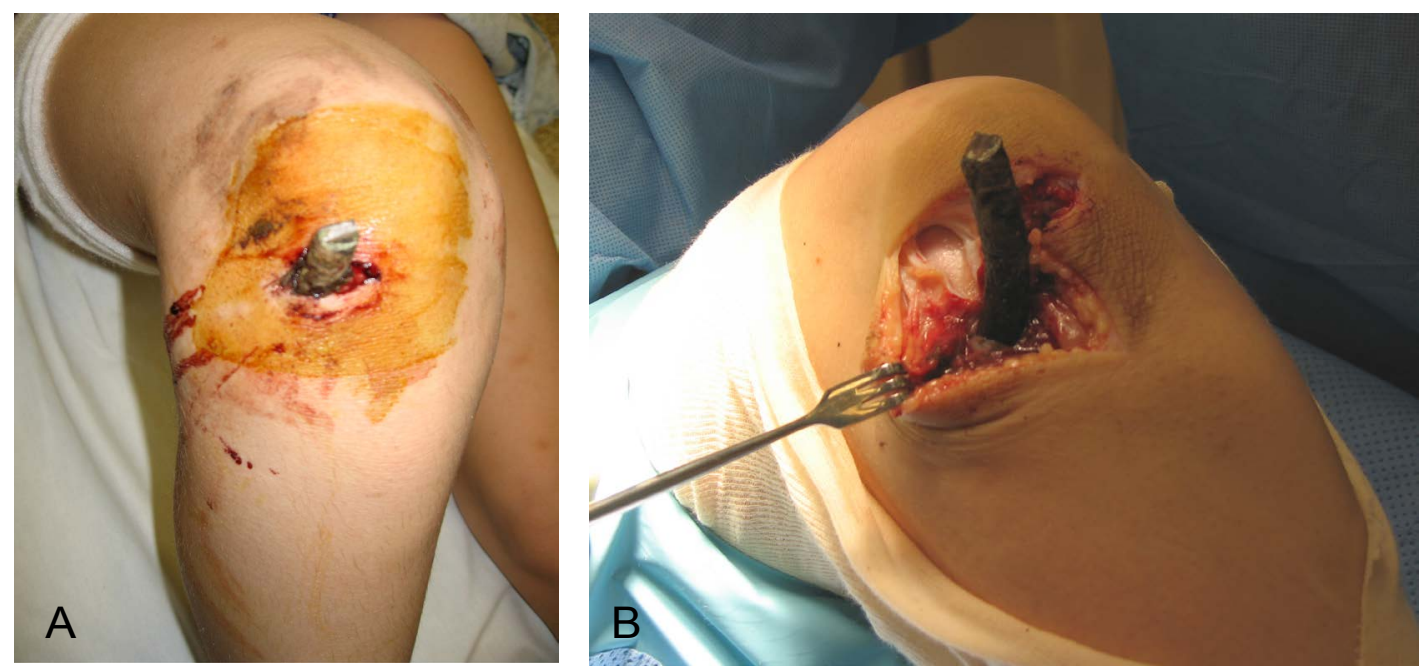

Figure 1: a) Part of rusted railing protruding out of the right knee; b) Per-operative photograph showing the rusted railing.

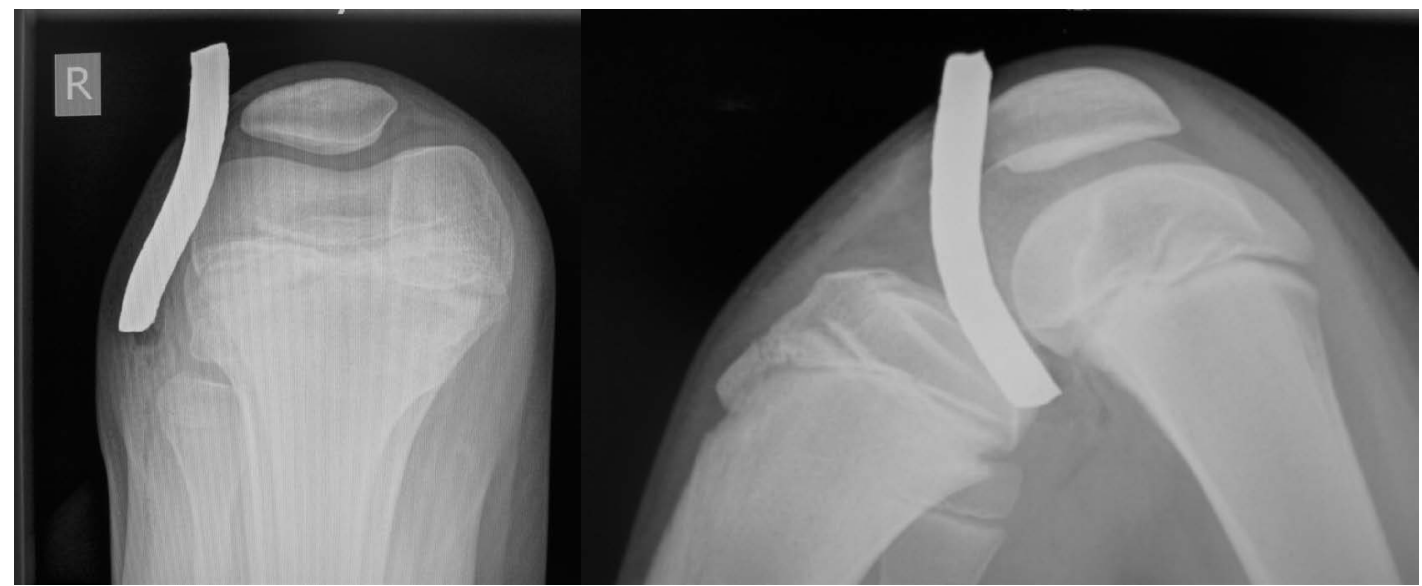

Figure 2: Radiographs of right knee.

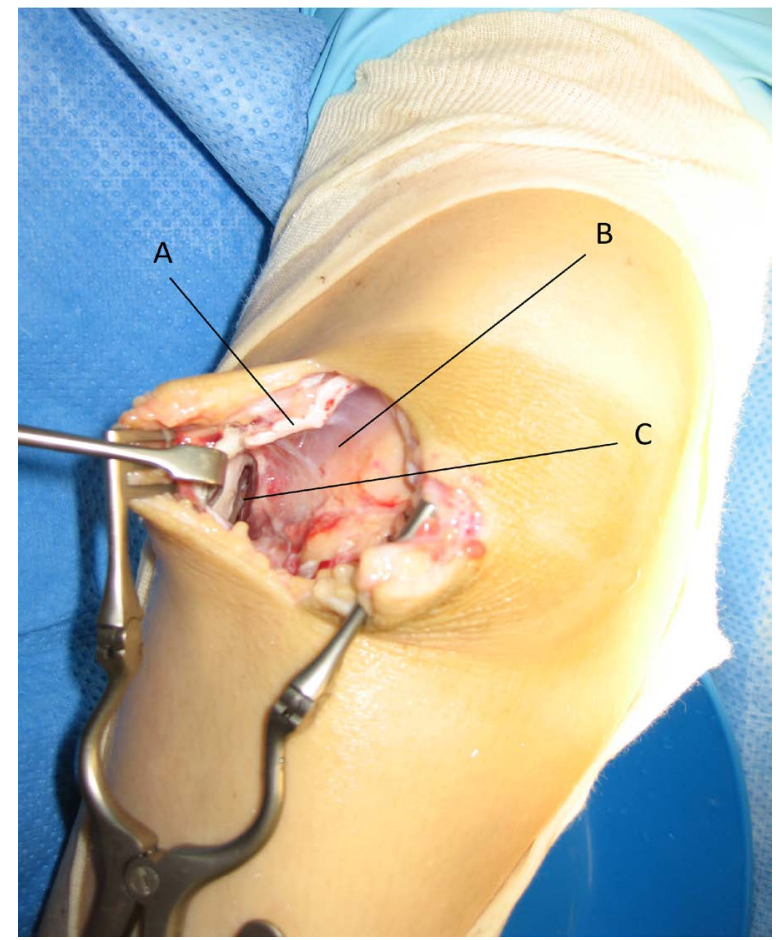

Figure 3: Per-operative photograph showing the potential space between capsule and synovium of the right knee. A - capsule; B - Synovium; C - Space between capsule and synovium. the superomedial aspect and there was no leakage of fluid into the space where the foreign body was found. The wound was thoroughly washed out and found to be clean. Intra-operative fluoroscopy showed no residual foreign body. The wound extension was closed. Patient was on intravenous broad-spectrum antibiotics for 48 hours and taken to theatre at 48 hours for a second debridement when it was found to be clean and a delayed wound closure was performed. Patient was allowed full weight bearing and range of movement exercises as tolerated. At 6 months follow up there was no evidence of infection in the wound. Patient had full range of movements in his right knee and no instability or features of meniscal pathology. He was back to playing football with no difficulties and hence, discharged from clinical care.

\section{Discussion}

Intra-articular foreign bodies can occur either due to direct or indirect injury and can be delayed presentation due to migration from local soft tissues. Most of these are caused by trauma and occasionally by self-harm.

Acute joint penetrating wounds require urgent debridement. If there is a foreign body that has entered the joint, then removal of foreign body reduces the risk 
of infection and prevents potential damage to the articular cartilage $[19,20]$. Radiographic examination show radio-opaque foreign bodies but not non-opaque substances like plastic. Computerised Tomography (C.T.) in radio-opaque foreign bodies is generally not recommended due to artefacts. Magnetic Resonance Imaging (M.R.I.) is contra-indicated due to potential for foreign body moving and causing more damage. C.T. and/or M.R.I. could assist in locating, assessing size and numbers of foreign bodies. Often, these penetrating injuries require wound extensions to assess and debride the wound. The wound extensions should be such that it would allow extensile exposures if required. The path of the foreign body should be followed carefully to avoid any iatrogenic injuries and removed completely, intact or otherwise. Often when the foreign body is inert and not involving articular cartilage, it does not cause any major problems. If the foreign body behaves as a third body, irritating the articular cartilage, it could lead to significant articular damage. However, in case of Intra-articular lead bullet, there is a possibility of lead toxicity occurring soon after the bullet injury or several years after the injury when the bullet is expected to be walled off by fibrous tissue [21,22].

Further investigations like Computerised Tomography could provide detailed imaging regarding site of the foreign body. Though Magnetic Resonance Imaging (M.R.I.) could provide more information regarding soft tissues and joint involvement, ferrous nature of most metallic objects precludes this investigation and in an acute situation, it is often difficult to assess the nature of the foreign body safely to consider M.R.I. In the case presented, possible mechanism of the foreign body tracking through the potential space between capsule and synovium include blunt foreign body (acting like an obturator) and the pliability of the thick synovium of the child's knee joint. This case is presented as a reminder that all foreign bodies that appear Intra-articular are not always Intra-articular and careful intra-operative assessment of the wound following the track of the foreign body is essential to prevent iatrogenic damage and prevent opening tissue planes unnecessarily.

\section{Conflict of Interest}

The author confirms that he does not have any competing interests in preparation of this article.

\section{References}

1. Gutierrez V, Radice F (2003) Late bullet migration into the knee joint. Arthroscopy 19: E15.

2. Boyle S, Talbot JC, Bismil Q, Schilders E (2010) Arthroscopic removal of a plastic soft drink bottle cap in the knee: A case report. Cases J 3: 72.

3. Mineo RC, Gittins ME (2003) Arthroscopic removal of a bullet embedded in the acetabulum. Arthroscopy 19: E121-E124.

4. Sansone V, Mora L, de Spirito D (2002) Arthroscopic retrieval of an unusual foreign body of the knee. Arthroscopy 18: E6.
5. Haspl M, Bojanic I, Pecina M (1996) Arthroscopic retrieval of metal foreign bodies from the knee joint after war wounds. Injury 27: 177-179.

6. Oldenburg M, Mueller RT (2003) Intra-articular foreign body after arthroscopy. Arthroscopy 19: 1012-1014.

7. Takizawa T, Akizuki S, Horiuchi H, Yasukawa Y (1998) Foreign body gonitis caused by a broken poly-L-lactic acid screw. Arthroscopy 14: 329-330.

8. Ilizaliturri VM Jr, Zarate-Kalfopulos B, Martinez-Escalante FA, Cuevas-Olivo R, Camacho-Galindo J (2007) Arthroscopic retrieval of a broken guidewire fragment from the hip joint after cannulated screw fixation of slipped capital femoral epiphysis. Arthroscopy 23: 227.

9. Devgan A, Mudgal KC (2007) An unusual case of foreign body knee that spontaneously migrated inside and out of the joint: Arthroscopic removal. Knee Surg Sports Traumatol Arthrosc 15: 758-760.

10. Sharma S, Rampurada A, Rees AJ (2007) A glass foreign body in the knee joint mistaken for $A L$ avulsion: An unusual case. Knee Surg Sports Traumatol Arthrosc 15: 766-768.

11. Lee BI, Choi HS, Kim JB, Min KD (2004) Arthroscopic retrieval of a very rare penetrating foreign body of the knee. Arthroscopy 20: 1071-1074.

12. Nassif JM, Gorczyca JT, Vanarthos WJ (1996) Unrecognized foreign body in the hip joint. J Orthop Trauma 10: 216-219.

13. Yeung Y, Wong JK, Yip DK, Kong JK (2003) A broken sewing needle in the knee of a 4-year-old child: Is it really inside the knee? Arthroscopy 19: E18-E20.

14. Duerinckx JF (2008) Case report: Subacute synovitis of the knee after a rose thorn injury: Unusual clinical picture. Clin Orthop Relat Res 466: 3138-3142.

15. Blake DR, Bacon PA, Scott CA, Potter AR (1981) Monoarthritis from blackthorn injury: A novel means of diagnosis. Br Med J (Clin Res Ed) 282: 361-362.

16. Sharma $H$, Meredith $A D$ (2004) Blackthorn injury: A report of three interesting cases. Emerg Med J 21: 392.

17. Theodorou SD, Vlachos $P$, Vamvasakis E (1981) Knee joint injury by mercury from a broken thermometer: Case report and review of the literature. Clin Orthop Relat Res 159-162.

18. Jandhyala R, Wilson A, Bhagat S, Lavelle J (2007) An unusual cause of locking. Knee Surg Sports Traumatol Arthrosc 15: 682-684.

19. Muschol M, Drescher W, Petersen W, Hassenpflug J (2004) Monarthritis of the pediatric knee joint: Differential diagnosis after a thorn injury. Arthroscopy 20: 865-868.

20. Rehman MA, Umer M, Sepah YJ, Wajid MA (2007) Bullet-induced synovitis as a cause of secondary osteoarthritis of the hip joint: A case report and review of literature. J Med Case Reports 1: 171.

21. DiMaio VJM, DiMaio SM, Garriott JC, Simpson P (1983) A fatal case of lead poisoning due to a retained bullet. Am J Forensic Med Pathol 4: 165-169.

22. Bolanos AA, Demizio Jr JP, Vigorita VJ, Bryk E (1996) Lead poisoning from an intra-articular shotgun pellet in the knee treated with arthroscopic extraction and chelation therapy. A case report. J Bone Joint Surg Am 78: 422-426. 